Article

\title{
Public attitudes towards e-cigarette regulations and policies in Taiwan
}

\author{
Chin-Shui Shih, Jean-Francois Etter \\ Institute of Global Health, Faculty of Medicine, University of Geneva, Switzerland
}

\begin{abstract}
Background: There are various approaches to e-cigarette regulation globally. In Taiwan, the term "e-cigarette" is not found in existing regulations, but health authorities apply explanatory notes derived from standing laws to e-cigarette. Taiwan health authority is in the process of regulative reform to include "e-cigarette" in standing tobacco law. Our objective was to investigate the public's attitudes towards potential policy options for e-cigarette regulations in Taiwan.

Design and Methods: We conduct an anonymous online survey in the general public. A questionnaire in Mandarin was posted on the website Stop-tabac.ch between July and November 2017.

Results: Participants ( $\mathrm{n}=236)$ were mostly male, young, highly educated, employed, and smoked or had smoked cigarettes in the past. Half were e-cigarette users. Four measures banning ecigarettes, labelling content and nicotine level and establishing a maximum-allowable nicotine level were supported by more than $70 \%$ of participants. Vaping status was strongly associated with support for most measures after controlling for other factors in multivariate models.

Conclusion: We documented attitudes of a self-selected sample of the general public in Taiwan regarding e-cigarette regulations and policies. These results may be useful to design studies in more representative samples and to inform e-cigarette regulations, policies and education campaigns.
\end{abstract}

\section{Introduction}

There are various approaches to e-cigarette regulations globally. ${ }^{1}$ In Taiwan, there is currently no law explicitly applying to ecigarettes, and the term "electronic cigarettes" or "e-cigarettes" does not currently appear in any tobacco related acts or laws. ${ }^{2,3}$ In 2009 the Taiwanese health authorities, after consulting experts, ${ }^{4}$ decided not to regard e-cigarettes as a tobacco product as defined under Article 2 of the Tobacco Hazards Prevention Act (THPA) and decided that e-cigarettes containing nicotine would be regulated under the Pharmaceutical Affairs Act (PAA) which requires registration and approval for manufacturing, importation and sale. E-cigarettes are not otherwise authorized..$^{5}$ E-cigarettes without nicotine are not regarded as pharmaceuticals, but advertisements and labels claiming medical effects are prohibited, and violators are fined..$^{5}$ Article 14 of the THPA, prohibits the production, importation, and sale of candy, snacks, toys, or anything in the form of tobacco cigarettes. Accordingly e-cigarette models that take the form of tobacco cigarettes violate this article, and the sellers are fined. ${ }^{6}$ The regulatory status of e-cigarettes is rapidly evolving along with various concerns. Multiple sectoral efforts ${ }^{7}$ and many administrative explanatory notes resulted in the current situation where six existing acts are applicable to e-cigarettes and their accessories.

Recent domestic and international events have caused authorities to reconsider Taiwan's e-cigarette policies. Court decisions ${ }^{8,9}$ have challenged the appropriateness of applying Article 14 of the THPA to e-cigarettes. International movements to regulate ecigarettes $^{1,10}$ have also prompted Taiwanese health authorities to re-consider their positions. Currently there are no e-cigarettes approved for manufacturing, sale and importation subject to the PAA in Taiwan. Despite their illegality and prohibition to use, ecigarette use, both containing and without nicotine, has been repeatedly documented in Taiwan, ${ }^{11}$ in surveys of adolescents ${ }^{12,13}$ and adults ${ }^{14,15}$ and some published papers providing theoretical analysis of ${ }^{16}$ and commentaries ${ }^{17}$ on regulatory policies. It was estimated that more than 38,000 minors use e-cigarette in Taiwan. ${ }^{18}$ In the USA, smokers generally agree that e-cigarettes should be regulated by the US FDA. ${ }^{19}$ In the UK, less restrictive e-cigarette policies were deemed more likely to be supported by ecigarette users. ${ }^{20}$ However, published data remain lacking for attitudes on and support of policy options in Taiwan.

We conducted an online survey in the general public in Taiwan. Our objective was to investigate the public's attitudes towards potential policy options for e-cigarette regulations in Taiwan.

Significance for public health

There are various approaches to e-cigarette regulation globally. The term "e-cigarette" is not found in existing regulations, but Taiwanese health authorities apply explanatory notes derived from standing laws to regulate e-cigarette. In Taiwan, there is no e-cigarette approved, but used. The Taiwanese health authorities face the challenge of how to best regulate it. Little is known about public attitudes toward current e-cigarette legislation. In addition, no literature is available about public attitudes to e-cigarette control measures that either applied already in other countries for e-cigarette or in Taiwan for tobacco control. This is the first study to examine the public attitudes towards e-cigarette legislations in Taiwan. Our findings on specific policy issues are useful in terms of identifying the need for information and education among policy makers, health professionals and the public, in Taiwan particularly, and in international community. 


\section{Design and Methods}

\section{Study design}

At the time of data collection, no e-cigarette was approved in Taiwan, but promotional activities were readily located on the Internet. In this situation, an on-line, self-administered and anonymous survey was deemed appropriate to reach the public, including e-cigarette users, ${ }^{21}$ given that $80 \%$ of Taiwanese residents have Internet access. ${ }^{22}$ We posted a questionnaire in Chinese on the website Stop-tabac.ch between July and November 2017. We then contacted and asked health authorities, associations, websites that sell e-cigarettes, discussion forums and vaper associations in Taiwan to publish a link to our survey: www.stopdependance.ch/tobacco/Ecig2017_tw/.

\section{Participants}

Eligible participants had to be at least 20 years old and reside in Taiwan. The survey provided no economic or other incentives. After reading the online informed consent form and agreeing to participate, participants were directed to the questionnaire. Participation was anonymous. The study protocol was approved by the Research Ethics Committee of the National Taiwan Normal University (201608HM005).

\section{Questionnaire}

The online questionnaire covered:

1. Questions related to level of agreement/disagreement with twelve control measures that are currently implemented in other countries ${ }^{1}$ and either are proposed amendments (from 1 to 5) or are not proposed amendments (from 6 to 12) to the THPA in Taiwan. 1) banning their use by minors, 2) banning their sale to minors, 3) banning their use during pregnancy, 4) banning their use at smoke-free public places and events, 5) banning all public promotion of e-cigarettes, 6) labelling content and nicotine level, 7) establishing a maximum-allowable nicotine level, 8) adding warning labels to packaging, 9) introducing e-cigarette taxation, 10) permitting sales over the internet, 11) permitting mail-order sales, 12) permitting sales in vending-machine. Participants' answered all these questions on 5-point Likert scales, response options were: 1= strongly agree, $2=$ agree, $3=$ neutral, $4=$ disagree, and $5=$ strongly disagree.

2. Gender, age, education level, region of residence, employment status, and monthly income.

3. Use of e-cigarettes (user/vaper, non-user/non-vaper) and smoking status (smoker, ever smoker, never smoked).

\section{Data analysis}

We checked IP address for validating residence and avoiding duplicate submissions. We assessed inter-group differences in support to the 12 control measures in sociodemographic characteristics, e-cigarette use and smoking behavior by either Mann Whitney test or Kruskal Wallis test. Variables that were statistically significant in bivariate models were included in stepwise multivariate regression models. All inferential tests were two-tailed with significance $\mathrm{p}<0.05$. We reported only control measures with variables that were statistically significant at $\mathrm{p}<0.05$.

\section{Results}

Of the 269 respondents, 236 provided complete valid answers and were included in further analysis. These 236 participants were young to middle age, mostly male, highly educated, employed, and of middle-to-low monthly income $(53.8 \%<40,000$ New Taiwan Dollars or approximate 1,330 USD per month). Nearly half resided in the northern region (more urban) of Taiwan, had smoked at some time in their life and were vapers (e-cigarette users).

\section{Bivariate analyses}

Four out of the five measures proposed in the THPA amendments (banning product promotion was the exception) were supported by $>70 \%$ of respondents. Two measures that are not in TPHA amendments (labelling packages for content and nicotine level and establishing a maximum-allowable nicotine level), also received more than $70 \%$ support. Banning e-cigarette use by and sale to persons under 18 years old received the highest percentage of support (93.1\% and $92.7 \%$, respectively), followed by labelling packages for content and nicotine concentration (88\%), banning use by pregnant women $(80.5 \%)$, setting a maximum-allowable nicotine level (75.2\%), and banning their use in smoke-free public places $(71.3 \%)$. Banning promotion/ advertising (59.8\%) and adding warning labels regarding e-cigarettes' health effects $(58.5 \%)$ received more tepid support. Measures receiving less than $50 \%$ support included adding an e-cigarette tax $(45.1 \%)$, allowing sales over the Internet $(40.2 \%)$, or via mail order $(34.2 \%)$, or in vending-machine $(29.8 \%)$.

Vaping status was significantly associated with the choice of eight out of these 12 measures, the 4 exceptions being: banning use and sales $<18$ years, establishing a maximum-allowable nicotine level, adding warnings labels and labelling content and nicotine levels. Females, never smokers and non-vapers were the most likely to support banning e-cigarette use by pregnant women, banning use in smoke-free public places and adding an e-cigarette tax. Male and current vapers agreed were the most likely to approve sales in vending-machine, via mail-order and on the Internet. Employed respondents were more supportive than their unemployed counterparts of banning e-cigarette use at smoke-free public locations, but less supportive of regulating internet and mail order (Table 1).

\section{Multivariate analyses}

The variables that were statistically significant in tests of bivariate associations were included in the multivariate models, and those showing significant $\beta$ value in 8 control measures are shown in Table 2. Current use of e-cigarette was the variable most frequently retained in the final multivariate models for eight policy options. Males showed more support for two access channels to ecigarettes: mail order and vending machines. Employment status remained in the final models for two control options. Smoking status was not significant at all.

\section{Discussion}

In this online survey of a self-selected sample of the general public in Taiwan, including many vapers, we found that banning ecigarette use by and sale to minors received the highest levels of support, followed by labelling content and nicotine levels, banning e-cigarette use during pregnancy, establishing a maximum-allowable nicotine level and banning their use at smoke-free public places. Banning promotion and putting warning labels were only supported by half the participants. Adding an e-cigarette tax and 
opening access channels received the least support. The strongest and most consistent predictor of regulation acceptance was the respondent's vaping status.

In a previous survey conducted by Taiwan's MOHW, ecigarette legislation received wide public support. ${ }^{23}$ In January 2017, the Taiwanese health authority proposed modifying the THPA to include an amendment on e-cigarettes, ${ }^{24}$ and this proposal was adopted by the Prime Minister on 21 December $2017^{25}$ then sent to the Legislative Yuan on 29 December 2017 for review. The review was still undergoing in autumn 2019. Except for those products approved by the PAA, this amendment suggests prohibiting the production, import, sale, display and promotion of ecigarettes and their component parts, substances and liquids. Under this new "dual" legislative scheme, the e-cigarette product would be explicitly regulated and subject to the approval of Taiwan's FDA, and legal use age and some use behaviors of e- cigarette will be regulated as combustible tobacco under the THPA.

The other e-cigarette related amendment includes the following control measures: i) banning e-cigarette use by persons under 18 years old; ii) banning their use by pregnant women; iii) banning all sales to persons under 18 years old; iv) designating non-smoking areas and public places where e-cigarette use is prohibited, and restricting their use to designated smoking area. Except prohibiting product and promotion, our survey found that these measures received high levels of support overall and medium-to-high levels of support among vapers. Thus, one might predict that the general public will be more favorable than vapers to e-cigarette regulations. These measures might be considered to some extent during legislative debates. Among the control measure that are not proposed in the THPA amendments, "labelling packages content and nicotine" and "establishing a maximum nicotine-allowable level"

Table 1. Level of support ${ }^{\S}$ for 12 selected control measures for e-cigarette.

\begin{tabular}{|c|c|c|c|c|c|c|c|c|c|c|c|c|c|c|}
\hline & & & & 5 proposed $\mathrm{f}$ & bans in the al & endments & & 7 non-propos & ed measures in $t$ & he amendn & ents & & & \\
\hline & & & $\begin{array}{l}\text { Use }<18 \\
\text { years }\end{array}$ & $\begin{array}{l}\text { Sale to } \\
<18 \text { years }\end{array}$ & $\begin{array}{l}\text { Use during } \\
\text { pregnancy }\end{array}$ & $\begin{array}{l}\text { Use at } \\
\text { non-smoking } \\
\text { public places } \\
\text { Agree }^{\#}\end{array}$ & $\begin{array}{l}\text { Pro- } \\
\text { motions }\end{array}$ & $\begin{array}{l}\text { Labelling } \\
\text { packages } \\
\text { content } \\
\text { and nicotine } \\
\text { Agree" }\end{array}$ & $\begin{array}{l}\text { Establish a } \\
\text { max-allowable } \\
\text { nicotine } \\
\text { level } \\
\text { Agree }^{\#}\end{array}$ & $\begin{array}{l}\text { Adding } \\
\text { warnings } \\
\text { labels } \\
\text { Agree" }\end{array}$ & $\begin{array}{l}\text { Adding } \\
\text { e-cig } \\
\text { tax } \\
\text { Agree }^{\#}\end{array}$ & $\begin{array}{l}\text { Sale via } \\
\text { internet }\end{array}$ & $\begin{array}{l}\text { Sale via } \\
\text { mail } \\
\text { order } \\
\text { Agree }^{\#}\end{array}$ & $\begin{array}{l}\text { Sale via } \\
\text { vending } \\
\text { machine } \\
\text { Agree }\end{array}$ \\
\hline Bivariate $^{\circ}$ & Characteristics & $\%$ & 93.1 & 92.7 & 80.5 & 71.3 & 59.8 & 88 & 75.2 & 58.5 & 45.1 & 40.2 & 34.2 & 29.8 \\
\hline Gender & Male & 58.7 & 90.5 & 90.4 & $71.7^{*}$ & $57 . .^{*}$ & $41.6^{*}$ & 88.2 & 71.7 & $42.3^{*}$ & $29^{*}$ & $59.9 *$ & $52.9 *$ & $46.4^{*}$ \\
\hline & Female & 41.3 & 96.8 & 95.9 & 93.8 & 89.7 & 85.6 & 87.6 & 80.2 & 81.4 & 68 & 12.4 & 7.3 & 6.2 \\
\hline Age & $20-29$ & 33.0 & 89.5 & 88.2 & $65.3^{*}$ & $59.8^{*}$ & $42.1^{*}$ & 87.0 & 68.8 & $42.1^{*}$ & $27.3^{*}$ & $64.9 *$ & $53.2^{*}$ & $48.1^{*}$ \\
\hline & $30-39$ & 43.0 & 94.0 & 93.9 & 85.9 & 73.5 & 62.0 & 85.7 & 79.0 & 62.0 & 51.0 & 28.3 & 29.0 & 24.0 \\
\hline & $>40$ & 24.0 & 96.3 & 96.4 & 90.9 & 85.7 & 78.6 & 92.9 & 78.2 & 75.0 & 60.7 & 26.8 & 16.4 & 14.3 \\
\hline Education & Graduate & 23.3 & 100 & 100 & 90.7 & $90.7^{*}$ & $78.2^{*}$ & 94.4 & 78.2 & $76.4^{*}$ & $60^{*}$ & $30.9^{*}$ & $31.5^{*}$ & 23.6 \\
\hline & University & 62.3 & 91.0 & 89.6 & 78.5 & 71.5 & 62.3 & 87.1 & 77.4 & 58.9 & 43.5 & 39 & 32.7 & 29.9 \\
\hline & High school & 14.4 & 91.2 & 94.1 & 73.5 & 39.4 & 20.6 & 81.8 & 61.8 & 29.4 & 29.4 & 58.8 & 44.1 & 38. \\
\hline Employed & Employed & 91.1 & 93.4 & 92.9 & 81.2 & $73.5^{*}$ & 60.7 & 88.3 & 77.1 & 59.3 & 46.5 & $37.9^{*}$ & $32.2^{*}$ & 28.4 \\
\hline & Unemployed & 8.9 & 90.5 & 90.5 & 73.7 & 50 & 52.4 & 85.7 & 57.1 & 52.4 & 33.3 & 61.9 & 52.4 & 42.9 \\
\hline Monthly & $<20 \mathrm{~K}$ & 10.2 & 95.8 & 91.7 & 68.2 & $56.5^{*}$ & 54.2 & $91.7^{*}$ & 62.5 & 54.2 & 29.2 & $58.3^{*}$ & 37.5 & $41.7^{*}$ \\
\hline income & $20 \mathrm{~K} \sim 40 \mathrm{~K}$ & 43.6 & 94.1 & 94.1 & 82.4 & 72.3 & 57.8 & 85.3 & 73.8 & 56.9 & 43.7 & 45.1 & 35.9 & 34 \\
\hline & $40 K \sim<60 K$ & 31.8 & 92.0 & 91.9 & 81.3 & 76.7 & 64 & 93.2 & 82.7 & 64 & 54.7 & 25.3 & 25.3 & 18.7 \\
\hline & $>60 \mathrm{~K}$ & 14.4 & 90.6 & 90.9 & 81.8 & 67.6 & 61.8 & 82.4 & 72.7 & 55.9 & 41.2 & 44.1 & 45.5 & 32.4 \\
\hline Smoking & Smoker & 28 & 90.8 & $92.3^{*}$ & 65.6 & 52.4 & 33.8 & 84.8 & 66.7 & 27.7 & $18.2^{*}$ & 60.6 & 54.5 & 53 \\
\hline & Ever & 27.5 & 90.8 & 89.1 & 70.8 & 55.4 & 44.6 & 92.2 & 75.4 & 52.3 & 33.8 & 67.7 & 52.3 & 40 \\
\hline & Never & 44.5 & 96.1 & 95.2 & 96.1 & 93.2 & 85.7 & 87.5 & 80.8 & 81.9 & 69.5 & 9.6 & 9.6 & 8.6 \\
\hline E-cig & Vaper & 50 & 90.6 & 90.5 & 66.4 & 52.6 & 32.5 & 87.2 & 69.5 & 32.5 & 19.5 & 70.1 & 59.3 & 50.8 \\
\hline & Non-vaper & 50 & 95.7 & 94.9 & $94.8^{*}$ & $89.7^{*}$ & $87.3^{*}$ & 88.9 & 81.2 & $84.7^{*}$ & $71.2^{*}$ & $10.2^{*}$ & $8.5^{*}$ & $8.5^{*}$ \\
\hline
\end{tabular}

$\$$ 5-point Likert item: $1=$ strongly agree, $2=$ agree, $3=$ neutral, $4=$ disagree, $5=$ strongly disagree; "combined "Strongly agree" and "Agree"; ${ }^{~}$ excluded region showed insignificantly in all measures; ${ }^{*} p<0.05$ for betweengroup differences.

Table 2. Multivariate analyses for 8 selected control measures* for e-cigarette.

\begin{tabular}{|c|c|c|c|c|c|c|c|c|c|}
\hline & & 3 proposed & I the amendment & & 5 non-pro & measures & amendme & & \\
\hline & & $\begin{array}{l}\text { Use during } \\
\text { pregnancy }\end{array}$ & $\begin{array}{l}\text { Use at non- } \\
\text { smoking public } \\
\text { places }\end{array}$ & Promotions & $\begin{array}{l}\text { Adding } \\
\text { warnings } \\
\text { labels }\end{array}$ & $\begin{array}{l}\text { Adding } \\
\text { e-cig tax }\end{array}$ & $\begin{array}{l}\text { Sale via } \\
\text { internet }\end{array}$ & $\begin{array}{l}\text { Sale via } \\
\text { mail order }\end{array}$ & $\begin{array}{l}\text { Sale via } \\
\text { vending } \\
\text { machine }\end{array}$ \\
\hline Multivariate & Non-vaper & 0.333 & 0.429 & 0.799 & 0.828 & 0.983 & -1.372 & -0.994 & -0.748 \\
\hline In the final & Male & - & - & & - & - & - & 0.291 & 0.337 \\
\hline Model\# & Employed & & 0.463 & & & & - & -0.334 & \\
\hline & Income & & 0.044 & & & & - & -0.115 & - \\
\hline & Age & - & -0.162 & - & - & - & - & - & - \\
\hline & Smoker & & & & & - & & & \\
\hline & Education & & 0.222 & 0.185 & - & - & - & - & \\
\hline
\end{tabular}

*Excluded measures showed non-significant "Ban use $<18$ years", "Ban sale to $<18$ years", "Establish a max-allowable nicotine level" and "Labelling packages content and nicotine"; \#significant bivariates were used in the stepwise regression; only showed $\beta$ value if significant: - non-significant; blank, not in the model; ${ }^{*} p<0.05$. 
received high support in our survey, including among vapers. These two measures are related to the product and product standards deserve being considered under PAA. "Adding warnings labels" received medium support, except not among vapers. The three options to broaden e-cigarette access channels were not supported even among vapers, possibly because of the difficulty to verify the age of customers. Taxes have been shown to reduce combustible tobacco consumption ${ }^{26}$ and some other countries ${ }^{10}$ have already added a tax on e-cigarette liquid or included a Value Added Tax (VAT), yet adding an e-cigarette tax was not included in the amendments drafted and was not widely supported by our respondents. In fact among vapers and smokers it was the least favored choice. Various taxation and other policies adopted by the $\mathrm{UK}^{27}$ including a registry where side-effects and safety concerns can be reported, and product safety standards could be considered in the amendments.

In our survey, vaping status was the most significant and consistent predictor in multivariable models. We were not surprised to find that only a few vapers supported restrictive control measures of adding an e-cigarette tax, banning e-cigarette promotion, and adding warnings to packaging. The vapers in our study were daily smokers when they first started to vape, but many of them stopped smoking thereafter. ${ }^{15}$ Smokers were highly supportive of some ecigarette policies ${ }^{19}$ including warning labels and having a minimum legal age of sale, and generally perceived e-cigarettes as less harmful than cigarettes. ${ }^{19,28,29}$ Smokers were in strong agreement with banning e-cigarette sale to and use by minors in our survey, but they largely disagreed with banning promotional activities, adding warning labels, and initiating an e-cigarette tax. We found smokers to be no more likely than non-smokers to support restricting e-cigarette promotion and use in smoke-free places. ${ }^{20}$

A strength of the currently reported anonymous, on-line, selfadministered survey is that it enabled us to access the hard-toreach e-cigarette users who may be reluctant to expose themselves under the current regulation in Taiwan where vaping is illegal. However, certain study limitations must be mentioned. First, selection bias, the participants were voluntary and could be different from non-participants. The participants were mostly males, younger, well- educated and employed compared with the general population. Vapers and ever smokers were over-represented in this self-selected sample. As such our results cannot be generalized beyond the subgroup who took part in this online survey, so the reader needs to be careful interpreting our findings. The accuracy of reporting cannot be ascertained as it was a self-administered online questionnaire. The size of our sample provided modest to strong statistical power. Our findings offer novel insights into attitudes towards and support of e-cigarettes regulations and control measures by a subgroup consisting largely of smokers and vapers. Further investigation needs to collect population-based data addressing the attitudes and opinions of the lay public as well as users and other stakeholders with respect to current and future ecigarette regulations and policies.

\section{Conclusion}

In this self-selected online sample of Taiwanese adults including a large proportion of vapers, generally accepted measures included banning e-cigarette sales to minors, banning their use by minors, during pregnancy, and at smoke-free public places (all the above were proposed in the THPA amendment) and establishing a maximum-allowable nicotine level (a measure that was not included in the THPA amendment) Non-vapers were more supportive than vapers of some restrictive policies including banning vaping at smoke-free public places, banning promotional activities, adding warning labels to packaging, and instituting an e-cigarette tax, but they were less supportive of regulations pertaining to access channels. Smokers were especially against adding an ecigarette tax. The strongest and most consistent predictor of regulation acceptance was the respondent's vaping status. Our results provide novel insights and can be useful to design studies to be conducted in representative samples and to inform future ecigarette regulations, policies and education campaigns.

Correspondence: Chin-Shui Shih, Institute of Global Health, Faculty of Medicine, University of Geneva, Campus Biotech, 9 Chemin des Mines, CH-1202 Geneva, Switzerland.

Tel. +41.22.9197076- Fax: +41.22.9197077.

E-mail: chinsshih@gmail.com; Chin-Shui.Shih@etu.unige.ch

Key words: E-cigarette; adult; public attitudes, on-line survey; regulations.

Contributions: CSS, participating in conceptualizing and research design, collecting, analyzing and interpreting data, discussion, drafting and revising the manuscript, approval and in charge of total article; JFE, senior author, participating in the study design, interpreting data, discussion, reviewing and revising the manuscript, responsible for final review and approval for publication.

Acknowledgements: The authors wish to thank staff at Stop-tabac for maintaining the questionnaires.

Conflict of interest: The authors declare no conflict of interest.

Funding: None

Ethics approval and consent to participate: The study protocol was approved by the Research Ethics Committee of the National Taiwan Normal University (201608HM005). Online informed consent was obtained from the participants; participation was anonymous.

Availability of data and materials: The data used to support the findings of this study are available from the corresponding author upon request.

Received for publication: 28 October 2019

Accepted for publication: 2 October 2020.

oCopyright: the Author(s), 2020

Licensee PAGEPress, Italy

Journal of Public Health Research 2020;9:1698

doi:10.4081/jphr.2020.1698

This work is licensed under a Creative Commons Attribution NonCommercial 4.0 License (CC BY-NC 4.0).

\section{References}

1. Kennedy RD, Awopegba A, León ED, Cohen JE. Global approaches to regulating electronic cigarettes. Tob Control 2017;26:440-5.

2. Ministry of Health and Welfare HPA. Tobacco hazards prevention act. Jan 23, 2009. Version in English. Available from: http://www.hpa.gov.tw/Bhpnet/web/rule/LawShow.aspx?No= 201406110001 
3. Ministry of Finance. Tobacco and alcohol tax act - Article Content - Laws \& Regulations Database of The Republic of China, 2017. Accessed on: 2019 May 1. Available from: https://law.moj.gov.tw/ENG/LawClass/LawAll.aspx?pcode $=\mathrm{G}$ 0330010

4. Health Promotion Administration, Ministry of Health and Welfare. Meeting Report of the Consultation on e-cigarette regulation. 2009.

5. Taiwan Ministry of Health and Welfare. Pharmaceutical Affairs Act. Dec 2015. Available from: https://law.moj. gov.tw/ENG/LawClass/LawAll.aspx?pcode $=$ L0030001

6. Health Promotion Administration, Ministry of Health and Welfare. E-cigarettes in the form of tobacco smoking pipe. 2014. Available from: https://health99.hpa.gov. tw/flipbook/21814/index.html $\# \mathrm{p}=31$

7. Health Promotion Administration, Ministry of Health and Welfare. Multi-sectoral Joint Efforts on E-cigarettes. Available from: https://health99. hpa.gov.tw/flipbook/21814/index.html\#p=24

8. Kaohsiung High Administrative Court. No.19 Chien-Shan 106. 2017. Available from: http://jirs.judicial.gov.tw/FJUD/index 1_S.aspx?p=tRrzEQzh7pSBsukxB\%2fFCi5a05biJ758LINVT LPymY0k\%3d

9. Kaohsiung High Administrative Court. No. 31 Chien-Shan 106. 2017. Available from: http://jirs.judicial.gov.tw/ FJUD/index_1_S.aspx?p=tRrzEQzh7pTmyQfmBE3J\%2fjC \% 2bKyzFBkeWuj8iKUQyqWc\%3d

10. Institute for Global Tobacco Control. Country Laws Regulating E-cigarettes: A Policy Scan. 2018. Available from: http://globaltobaccocontrol.org/e-cigarette/country-laws-regulating-e-cigarettes

11. Health Promotion Administration, Ministry of Health and Welfare. E-cigarettes Page. 2013. Available from: https://www.hpa.gov.tw/Pages/List.aspx?nodeid=444

12. Chen P-C, Chang L-C, Hsu C, Lee Y-C. Dual use of ecigarettes and traditional cigarettes among adolescents in Taiwan, 2014-2016. Nicotine Tob Res 2019;21:48-54.

13. Chen P-C, Chang L-C, Hsu C, Lee Y-C. Electronic cigarette use and attempts to quit smoking cigarettes among adolescents in Taiwan. J Adolesc Health 2019;64:99-106.

14. Chang H-C, Tsai Y-W, Shiu M-N, et al. Elucidating challenges that electronic cigarettes pose to tobacco control in Asia: a population-based national survey in Taiwan. BMJ Open 2017;7:e014263.

15. Shih C-S, Etter J-F. The profile of e-cigarette users: Results of an online survey in Taiwan. Asia Pac J Health Sci 2019;2019:219-27.

16. Jiang TH, Cheng LM, Hawkins MA. A study of regulatory policies and relevant issues concerning electronic cigarette use in Taiwan. Int J Health Plann Manage 2017;33:e119-30.
17. Gao W, Sanna M, Huang L-L, et al. Juggling two balls Smoking (re)normalization and harm reduction: E-cigarettes Facts and misconceptions in Taiwan. Asia Pac J Public Health 2018;30:328-31.

18. Health Promotion Administration, Ministry of Health and Welfare. E-cigarettes pose threat to teen health: HPA. 2016. Available from: https:/www.hpa.gov.tw/EngPages/ Detail.aspx? nodeid $=1038 \&$ pid $=10547$

19. Wackowski OA, Delnevo CD. Smokers' attitudes and support for e-cigarette policies and regulation in the USA. Tob Control 2015;24:543-6.

20. Brose LS, Partos TR, Hitchman SC, McNeill A. Support for ecigarette policies: a survey of smokers and ex-smokers in Great Britain. Tob Control 2017;26:e7-15.

21. Wright KB. Researching internet-based populations: Advantages and disadvantages of online survey research, online questionnaire authoring software packages, and web survey services. J Comput-Mediat Commun 2005. doi: 10.1111/j.1083-6101.2005.tb00259.x

22. Taiwan Network Information Center. A survey on broadband internet usage in Taiwan - A summary report. 2017. Available from: https://www.twnic.net.tw/download/200307/20170721d.pdf

23. Health Promotion Administration, Ministry of Health and Welfare. Taiwan Tobacco Control Annual Report 2018. Available from: https://health99.hpa.gov.tw/media/public/ pdf/22077.pdf

24. Health Promotion Administration, Ministry of Health and Welfare. Preview: Tobacco Hazards Prevention Act. 2017. Available from: https://join.gov.tw/policies/detail/4c5cbfeba093-46fc-8f9b-f7aad0a19af2

25. Executive Yuan. The Executive Yuan approved the amended draft of Tobacco Hazards Prevention Act. 2.16.886.101.20003. 2017. Available from: https://www.ey.gov.tw/News_Content2. aspx?n=F8BAEBE9491FC830\&s=ABF2096B17CC 2940

26. WHO. Taxation. Available from: http://www.who.int/tobacco/economics/taxation/en/

27. Gov.uk [Internet]. Evidence review of e-cigarettes and heated tobacco products 2018: executive summary. 2018. Available from: https://www.gov.uk/government/publications/ecigarettes-and-heated-tobacco-products-evidence-review/evidence-review-of-e-cigarettes-and-heated-tobacco-products2018-executive-summary

28. Dockrell M, Morrison R, Bauld L, McNeill A. E-cigarettes: prevalence and attitudes in Great Britain. Nicotine Tob Res 2013;15:1737-44.

29. Tan ASL, Bigman CA. E-cigarette awareness and perceived harmfulness: prevalence and associations with smoking-cessation outcomes. Am J Prev Med 2014;47:141-9. 